\title{
A condom in every jail cell
}

$\mathrm{S}$ ensitivity training for health care workers, improved counselling for HIV-infected men and the provision of condoms and lubricants in prisons and other places where men have sex with men are among solutions being advanced to combat rising HIV/AIDS prevalence rates in major cities of South Africa.

The solutions are among measures urged by participants to the first South African conference, the Top2Btm MSM [men who have sex with men] Symposium, held to "brainstorm about prevention, care and treatment for MSMs" in the wake of new data which indicates that the HIV prevalence rates among men in Africa's southernmost nation are soaring.

Global Forum on MSM \& HIV data indicated that the HIV prevalence rate in the Johannesburg urban area of Soweto, with a predominantly black population, was $50.4 \%$ among of 378 men who have sex with men, while the rate in the city of Durban was 44\% (among 266 men). The South African government pegged the rate in Cape Town, another city popular with tourists, at $25 \%$ but did not indicate the sample size.

Nationally, $7.9 \%$ of South African men and $13.6 \%$ of women are infected with HIV. The high percentages in major cities, however, compelled representatives of South African homosexual groups, health providers and researchers to gather in search of solutions.

Delegates to the May conference urged a host of remedial measures, led by a call upon various levels of government, as well as religious and community groups, to support measures aimed at discouraging homophobia and destigmatizing anal sex.

Although South Africa is the only country in Africa that does not outlaw homosexuality, persecution is common. As a consequence, few homosexuals are tested for HIV, and only $18 \%$ of men who have sex with men in South Africa know their HIV status, Dr. Greg Jonsson, a psychiatrist at the Chris Hani Baragwanath Academic Hospital in Soweto, told the symposium.

Minister, Aaron Motsoaledi, has pledged to commission more research on sensitivity training for health care workers. Motsoaledi also called for more national research on the extent to which HIV has infected the MSM community. "We only have small regional studies to rely on at this point."

Others offer more prescriptive solutions.

The government should provide access to protective measures such as condoms and water-based lubricants in prisons and other places where forced and consensual anal sex is prevalent, says De Swardt.

Providing lubricants is vital, says Dr. Chris Beyrer, director of the Johns Hopkins Fogarty AIDS International Training and Research Program in Baltimore, Maryland. He explains that due to lack of natural lubrication, anal sex is highly likely to

Stigmatization is an issue, says Dr. James MacIntyre, symposium organizer and CEO of the Cape Town-based Anova Health Institute which hosts Health4Men, a program that provides health care for men who have sex with men. "Internalized homophobia and higher levels of HIV stigma are associated with negative outcomes, especially romantic loneliness, poor self-esteem and lack of social support," he says.

The institute has organized outreach programs to sensitize the broader community that people with alternative sexual preferences are not necessarily "wrong, criminal or a threat" to society, says Glen De Swardt, coordinator of the Health4Men program.

De Swardt says there is also a need for the national health system to provide sensitivity training for health workers who provide medical services for HIV-infected men.

To that end, South Africa's Health cause bruising of both the penis and the rectum, so the likelihood of HIV infection is up to 18 times higher than during penile-vaginal sex.

Still others argue there's a need to improve psychiatric support services for homosexuals who become HIV-infected, as they often are afraid to seek help and turn to drug use. “A young men's survey showed us that $66 \%$ of young MSM reported illicit drug use," says Jonsson.

HIV-positive men who have sex with men are more likely to suffer from anxiety or depression, or to suffer from "HIV-associated neuro-cognitive disorder (which affects such brain functions as concentration, memory and thought)," adds Dr. Kevin Stollof, a psychiatrist at Ivan Toms Men's Centre for Men's Health in Cape Town. Innocent Madawo, Pretoria, South Africa

CMAJ 2011. DOI:10.1503/cmaj.109-3934 